\title{
The impact of ISO 14001 on the operations management of wooden furniture manufacturers in Malaysia
}

\begin{abstract}
A survey of ISO 14001 certified and non-certified wooden furniture manufacturers in Malaysia revealed that the low cost-benefit factor was the main reason that deterred the adoption of the standard. However, the adoption of ISO 14001 resulted in the production of green furniture, the use of environmental friendly materials and technologies, retraining of the workers and waste reduction. Consequently, the adoption of the ISO 14001 environmental management system resulted in a more cost-effective wooden furniture production, contrary to previous perception.
\end{abstract}

Keyword: ISO 14001; Operations Management; Wooden Furniture 